See Article page 41 .

\section{Commentary: Methods are the investigator's lens}

\author{
Jakob Vinten-Johansen, PhD
}

The report by Momin and colleagues ${ }^{1}$ describes differences in myocardial (with respect to right atrial) temperature between open-sternum and robotically assisted approaches to surgical mitral valve repair. Right atrial temperature, which was used to represent left ventricular temperature, was measured with a noncontact infrared thermometer aimed at the body of the right atrium.

Two major concerns are raised by the data presented. First, the temperature of the robotic group was cooler at the start of bypass, presumably before extracorporeal cooling was initiated, whereas the open group achieved the target cooling temperature of $32^{\circ} \mathrm{C}$ after start of bypass, as expected. Second, there was no "myocardial" hypothermic response in the robotic group after antegrade infusion of $4^{\circ} \mathrm{C}$ del Nido cardioplegia solution, in contrast to the hypothermic trajectory shown in the open group.

Relevant to both concerns, one may question the accuracy of the infrared thermometer. After all, the data are revealed through the lens provided by the methods. The Fluke 62 Max (Fluke Corporation, Everett, Wash) infrared thermometer is a handheld device that measures the temperature of a surface area 0.1 in diameter related to the distance between device and target marked by a laser spot, or a 10:1 distance-to-spot size ratio. A technical specialist at the company stated that temperatures can accurately $( \pm 1.5 \%)$ be measured in tissue as well as other materials. The temperature measurements are unaffected by moisture, surface texture, or angle of incidence between the device and the target surface. The instrument is therefore likely accurate in an in vivo environment, although it

From the Division of Cardiothoracic Surgery, Department of Surgery, Emory University, Atlanta, Ga.

Disclosures: Author has nothing to disclose with regard to commercial support.

Received for publication Dec 16, 2019; revisions received Dec 16, 2019; accepted for publication Jan 3, 2020; available ahead of print Feb 6, 2020.

Address for reprints: Jakob Vinten-Johansen, PhD, 159 Montauk Ct, Clemmons, NC 27012 (E-mail: jvinten@emory.edu).

JTCVS Techniques 2020;1:46-7

2666-2507

Copyright (C) 2020 The Author(s). Published by Elsevier Inc. on behalf of The American Association for Thoracic Surgery. This is an open access article under the CC BY-NC-ND license (http://creativecommons.org/licenses/by-nc-nd/4.0/).

https://doi.org/10.1016/j.xjtc.2020.01.014

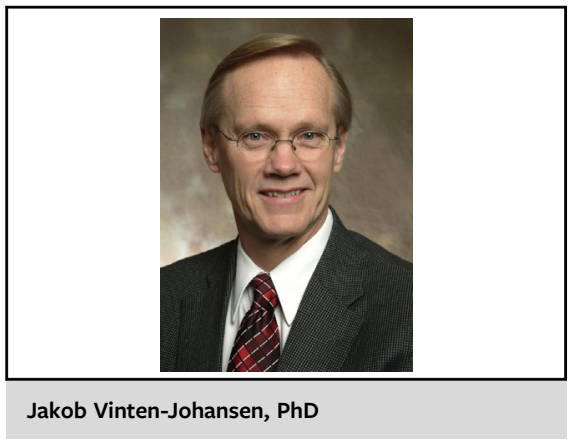

CENTRAL MESSAGE

Methods predetermine the observations that provide data to

be interpreted. It is important to understand the accuracies and limitations of methods used in studies.

would have been appropriate to correlate measurements with other standard direct techniques. Issues with accuracy, however, would not explain the temperature differences between the groups at the start of bypass or during cardioplegia.

The second concern regards the absence of hypothermia during cardioplegia-induced arrest in the robotic group. One is tempted to speculate that delivery of cold $\left(4^{\circ} \mathrm{C}\right)$ cardioplegia was inadequate, because delivery techniques and devices differed between the groups. There are no data on intraoperative arrest, however, such as time to arrest, incidence of escape beats, or reanimation, that would provide insight into the adequacy of cardioplegia delivery. One may also question whether measuring temperature in the body of the right atrium accurately reflects temperature of the ventricular myocardium, because vascular supply may limit the delivery volume of cardioplegia, and the chamber is thin and more affected by different external sources of temperature, such as contiguous structures. Although this may explain, in part, temperature differences at the start of bypass, environmental differences would not satisfactorily explain the lack of hypothermic response to cold cardioplegia.

Alternative explanations of temperature differences consider how different bypass circuitry affects right atrial temperature, or whether the temperature in the atrium reflects that in the left ventricle. Details of extracorporeal bypass are missing in the report but can be inferred from a previous report. ${ }^{2}$ Venous drainage in the open group presumably involves bicaval or 2-stage 
cannulation, by which venous return may be more fully harvested. Coronary venous drainage passing through the right atrium would likely lower atrial temperature during the cardioplegia period. In contrast, incomplete harvesting of venous return by femoral vein and superior vena caval cannulation used in the robotic group may allow admixture of systemic blood with cold coronary venous effluent during cardioplegia delivery, which would offset the degree of hypothermia as transmitted to the right atrium. A hypothermic temperature trajectory may therefore not be observed in the robotic group. Testing this alternative explanation would require simultaneous measurement of left ventricular tissue temperature directly by infrared thermometer or by direct contact probes, typically placed in the left ventricular septum, or by both methods simultaneously.
Although the data appear to suggest that myocardial temperatures differ between open sternotomy and closed robotic approaches to mitral valve surgery, the methods may not be measuring temperature in the left ventricular myocardium as intended by the investigators. The design of a study testing myocardial temperature differences between open and robotic approaches either should include direct left ventricular temperature or should confirm whether measurements in other sites are representative of the intended target.

\section{References}

1. Momin AA, Chemtob RA, Lopez DC, Gillinov AM, Wierup P, Mick SL. Open sternum, cooler heart: the effect of surgical approach on myocardial temperature. J Thorac Cardiovasc Surg Tech. 2020;1:41-2.

2. Gillinov AM, Suri R, Mick S, Mihaljevic T. Robotic mitral valve surgery: current limitations and future directions. Ann Cardiothorac Surg. 2016;5:573-6. 